\title{
Fragmented governance, the urban data ecosystem and smart city-regions: the case of Metropolitan Boston
}

\section{Rob Kitchin \& Niamh Moore-Cherry}

To cite this article: Rob Kitchin \& Niamh Moore-Cherry (2020): Fragmented governance, the urban data ecosystem and smart city-regions: the case of Metropolitan Boston, Regional Studies, DOI: 10.1080/00343404.2020.1735627

To link to this article: https://doi.org/10.1080/00343404.2020.1735627

\section{曲 Published online: 30 Mar 2020.}

Submit your article to this journal $\widetilde{x}$

Llll Article views: 654

\section{Q View related articles $\sqsubset$}

View Crossmark data ¿

Citing articles: 2 View citing articles $\square$ 


\title{
Fragmented governance, the urban data ecosystem and smart city-regions: the case of Metropolitan Boston
}

\author{
Rob Kitchin $^{\mathbf{a}} \odot$ and Niamh Moore-Cherry ${ }^{\mathbf{b}} \odot$
}

\begin{abstract}
Through an empirical focus on Metropolitan Boston, this paper examines the effects of territorial politics and fragmented metropolitan governance on an urban data ecosystem and endeavours to enact a smart city-region. The fragmented governance of Metro Boston reduces scales of economy and produces interjurisdictional data incompatibilities that limit spatial intelligence, foster back-to-back planning and stifle the benefits of open data. Highlighted is the irony that in order to address fragmented governance, there is a need for greater information-sharing, but that very activity is stymied because of a deeply rooted localist agenda that resists more collaborative, metro-regional governance arrangements.
\end{abstract}

\section{KEYWORDS}

fragmented governance; metropolitan governance; open data; smart cities; Boston; territorial politics

\section{JEL R58}

HISTORY Received 21 September 2019; in revised form 19 February 2020

\section{INTRODUCTION}

In their paper on the drive to create smart cities, Kitchin, Coletta, Evans, Heaphy, and Mac Donncha (2017a) note that, despite significant enthusiasm and investment, actually existing smart urbanism continues to be partial and fragmented, only moderately embedded within city administrations (see also Karvonen, Cugurullo, \& Caprotti, 2018; Shelton, Zook, \&Wiig, 2015). They detail, from the perspective of a city administration, reasons why the smart city has proven difficult to implement in practice, including: entrenched organizational structures and ways of working; internal politics and competing interests; constrained resourcing and competing demands; a deficit of political and public support; legacy systems and lack of mature, proven technological systems/solutions; and external resistance and push-back. A further key factor is a fractured system of political administration across city-regions.

This paper examines the effects of territorial politics and fragmented metropolitan governance on an urban data ecosystem and endeavours to enact a smart city-region. There is a well-established literature on the territorial and scalar politics of local and regional governance regimes of cities and their effects on the operations of city administrations (Frug \& Barron, 2008; Kreukels, 2003; Norris, 2017; Tewdwr-Jones, 2012). Increasingly, the city-regional or metropolitan scale is considered the most appropriate to drive urban and regional development in order to counter the negative effects of multi-jurisdictional governance (Ahrend, Farchy, Kaplanis, \& Lembcke, 2014). The form this takes can vary from highly institutionalized forms of metropolitan governance, such as in Paris, to more loosely based governance networks in cities such as New York (Nelles, Gross, \& Kennedy, 2018). The nature of such administrative arrangements is shaped by preceding events, local history and the existence of a 'regional' culture, all of which can act as barrier to effective interjurisdictional cooperation (Nunn \& Rosentraub, 2007). However, while attention has been paid to emerging notions of 'smart governance', that is, using smart city technologies to manage public administration and service delivery (Gil-Garcia, 2012; Goldsmith \& Crawford, 2014; Ruhlandt, 2018; Scholl \& AlAwadhi, 2016), little attention has been paid to the relationship between multi-jurisdictional governance and the intra-urban data ecosystem.

City administrations, and other public agencies and non-governmental organizations (NGOs), have long generated and used data about citizens, infrastructures and services to help manage operations and govern. The use of such data intensified with the introduction of digital systems throughout the latter third of the 20th century (Kitchin, Lauriault, \& McArdle, 2017b; Light, 2004).

\section{CONTACT}

a (Corresponding author) Rob.Kitchin@mu.ie

Maynooth University Social Sciences Institute, Maynooth University, Maynooth, Ireland. 
This has further deepened in the data-driven smart city age, with digital data now routinely generated and used within and across municipal departments to aid their work (Barns, 2016; Townsend, 2013). A plethora of digital technologies is being deployed across different domains, including: egovernment systems, city operating systems, centralized control rooms, digital surveillance, predictive policing, intelligent transport systems, smart grids, sensor networks, building management systems and civic apps. These systems generate big data - real-time, exhaustive, fine-grained streams of data - that can be harnessed to provide urban intelligence and reshape the practices and processes of public administration (Townsend, 2013). Such reuse can be internally facing; for example, providing intelligence on the efficiency and effectiveness of operations and enabling simulations of future scenarios (Goldsmith \& Crawford, 2014). It can also be externally facing; for example, creating civic apps and urban dashboards to improve quality of life through the provision of real-time information about the city (Kitchin, Lauriault, \& McArdle, 2015). Increasingly, public bodies are under pressure to share their data through open data portals to enable citizens and companies to create their own urban intelligence and derived products such as apps (Barns, 2016, 2018). However, to date open data have been piecemeal and largely restricted to administrative data rather than more valuable, real-time operational data, and often suffer from various quality issues (McArdle \& Kitchin, 2016).

Creating coherent, harmonized data sets becomes an even greater challenge in a fragmented city-region composed of multiple jurisdictions. Depending on the governance and legal structure of the city, public bodies may be operating quite independently of each other, producing, using and curating data in diverse ways with little incentive to coordinate technical approaches or share data. Further, infrastructure fragmentation can arise from choices and constraints concerning technologies, protocols, standards and contractors, and how they are implemented and evolve. Depending on where one lives and works in a metropolitan area, data-driven urbanism can be technically constituted and administratively and operationally practised in quite different ways, leading to variances in the delivery and quality of public services and, in some cases, compounding existing inequalities. This paper examines the character and consequences of fragmented governance structures with respect to the urban data ecosystem of Metropolitan Boston (henceforth Metro Boston). After detailing the case study and methodology, it maps out the urban governance and data landscape of Metro Boston, details the issues and consequences of fragmented governance, and the implications for the emergence of a metropolitan data commons.

\section{CASE STUDY: METROPOLITAN BOSTON}

Metro Boston is strongly polycentric in nature consisting of 101 administrative cities and towns (Figure 1) served by the Metropolitan Area Planning Council (MAPC). According to US Census Annual Population Estimates, the population of Metro Boston was 3.2 million in 2013 (48\% of the state population) (MAPC, 2015). Cities and towns in Metro Boston can vary substantially in population size with the City of Boston the largest, estimated to be 653,103 in 2013, the next largest Cambridge, estimated to be 112,069 , and 88 municipalities having less than 50,000 population (the smallest is just over 4000 residents). ${ }^{1}$

The complex political administrative geography of Metro Boston is rooted in its historical development, having evolved to include long-standing incorporated communities with strong-rooted, local identities, making it different from other cities in the United States (Euncher, 2003; Horan, 2009; O'Connell, 2002). In the absence of politically strong counties, cities and towns operate within a system of 'home rule' in which 'residents have the opportunity to create their own charters for the governance of their community' (Euncher, 2003, p. 25). Each of the 101 cities and towns has local autonomy, administers various forms of local governance and services, and can collect property taxes. Cities are run either by a strong, elected mayor and weak council of government, or by two forms of city manager. Towns are 'organized around open town meetings, a representative town meeting, or elected selectmen or councillors' (p. 26). Larger towns hire professional staff to conduct day-to-day business; others rely on boards and commissions made up of citizens serving in a part-time or voluntary capacity. The economic and land-use profile of cities and towns is diverse and thus their ability to raise local tax income and deliver services varies enormously.

While not a unique situation, the lack of a regional government with executive powers means there is little direct oversight and coordination of the 101 cities and towns. Instead, they act largely independently of each other and there is little history of cooperation. Indeed, mesoscale governance is largely lacking in Massachusetts and there are few general-purpose government bodies operating above the local scale (Euncher, 2003). The exception is the MAPC, although functionally it is advisory and provides some consultancy and mapping services, but has no enforcement powers. State-level agencies do deliver some services that impact locally (e.g., state roads, state police) and support services for public administration (e.g., Mass IT, Mass GIS), but leave municipalities to govern locally (Horan, 2009). Other governmental agencies that practice local service delivery include: the Massachusetts Bay Transport Authority (MBTA), which services all 101 towns and cities; the Boston Regional Intelligence Centre, which coordinates security policing across nine municipalities; the Massachusetts Housing and Finance Agency (MHFA), which provides affordable housing units and finance to low-income households; and the Massachusetts Water Resources Authority (MWRA), which provides water and sewer services in full or part to 61 cities and towns, most of which are in Metro Boston. Adding to this complex governance landscape are special-purpose governments - elected and appointed boards, and commissions - that run specialized functions of government, and non-governmental bodies (e.g., charities, foundations, community groups). All these administrative entities have 


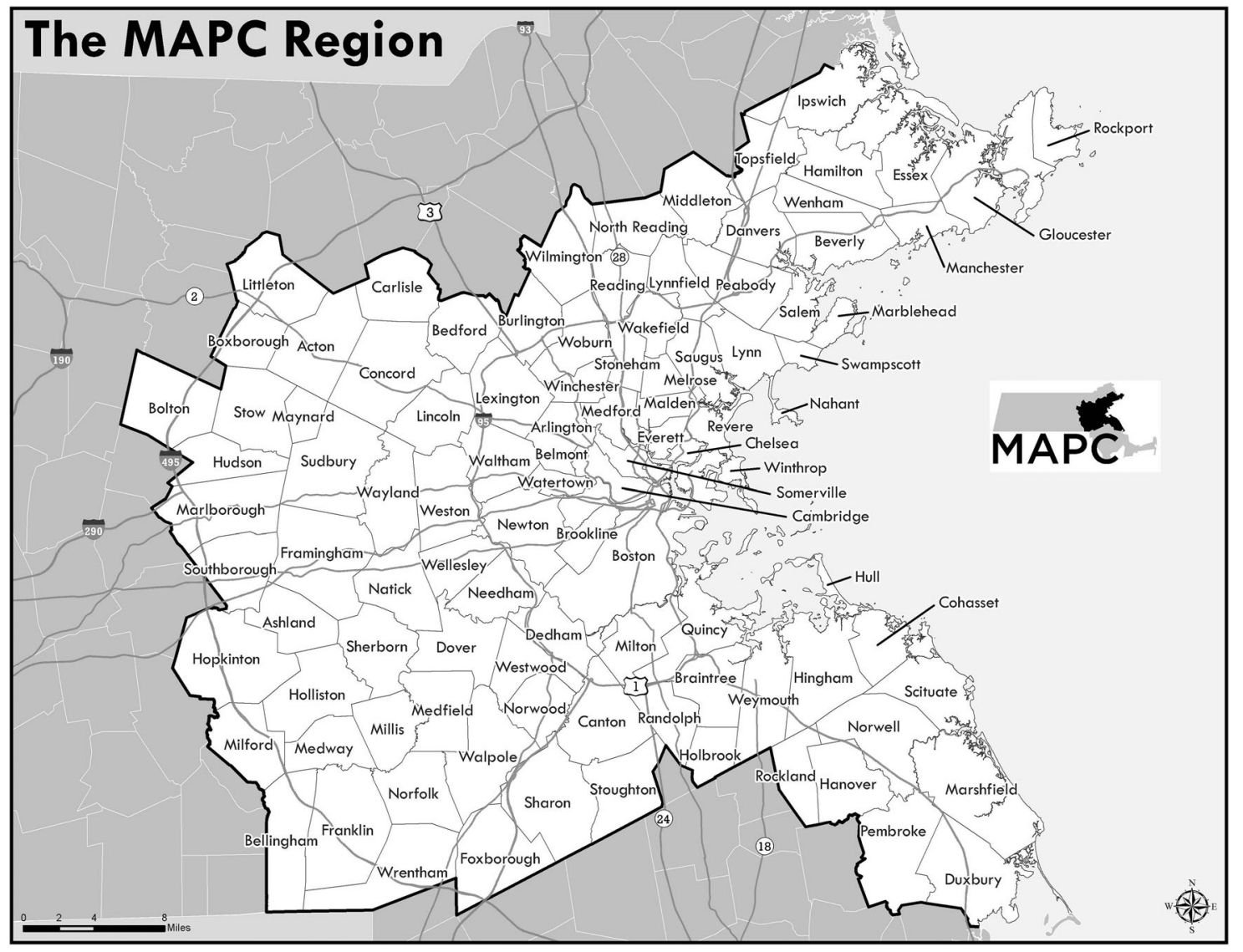

Figure 1. Metropolitan Boston.

Source: Lily Perkins-High and Tim Reardon, Metropolitan Area Planning Council (MAPC), Boston.

varying levels of autonomy and can have conflicting missions and practices.

These actors and institutions face significant dilemmas when a new approach - in this case, smart urbanism, datadriven approaches and open data - stand in opposition to long-standing traditions and beliefs (Bevir \& Rhodes, 2003). Metro Boston has the worst-case scenario for effective governance structures, ranking highly on the metropolitan power diffusion index and the state centralization index (Hamilton, Miller, \& Paytas, 2004). Characterized as state-centric (Miller \& Lee, 2011), local government officials are twice more likely to interact with state officials as among themselves. This situation is further complicated by numerous political and business lobby groups, policy think-tanks, and university research policy institutes and centres that all seek to influence the policy agenda and actions of government. Despite the functional urban area stretching beyond and crossing municipal boundaries and the widely acknowledged benefits of cooperation at the city-regional scale (Henderson, 2015; Nelles, 2013), a sense of 'metro-phobia' (Moore-Cherry \& Tomaney, 2019) is clearly apparent.

This paper explores the impact of fragmented governance on the urban data ecosystem through 24 interviews/ focus groups with key stakeholders in the Metro Boston region. The fieldwork took place in April and September 2016, with a particular focus on the cities of Boston, Cambridge and Somerville, which border each other, and each of which has started to embrace data-driven urbanism. In total, 37 stakeholders were interviewed through 17 oneon-one interviews, and six focus groups. Two public talks were also recorded and transcribed with permission. The interviewees included representatives from the cities of Boston (including their open data, mapping, performance metrics and New Urban Mechanics teams, and the Boston Redevelopment Authority $(\mathrm{BRA})^{2}$ ), Cambridge (open data team) and Somerville (Somerstat), MAPC (Data Services Department), the Commonwealth of Massachusetts (Executive Office of Technology Services and Security), workers in two data-focused companies, and academics in Harvard, MIT, Northeastern, Boston University and Emerson College. The public sector interviews were mainly senior personnel in leadership positions, including the heads of data teams and chief data/information officers, as well as project staff. The academics were all lead investigators or key personnel working in laboratories and teams researching aspects of data-driven smart urbanism and had collaborated with government stakeholders in the Metro Boston region. The one exception was an expert on the legal and political administration of Massachusetts.

The interviews and focus groups took a conversational guided approach (Patton, 1990). Typically, the interview opened with a general conversation about the work of the interviewee and their organization, and the extent to which their work sought to enact data-driven/smart urbanism. It proceeded to discuss the specific work of particular 
programmes or projects and any salient issues and challenges. The questioning then explored issues of collaboration across stakeholders in the region and the broader urban data ecosystem and finished with an evaluation of Boston as an 'actually existing smart city' (Shelton et al., 2015). Since the empirical research is based on interviews conducted in 2016, the analysis is limited to this period and before and does not discuss any subsequent developments.

\section{A FRACTURED URBAN DATA ECOSYSTEM}

Given the fragmented administrative geography of Metro Boston, it is perhaps no surprise that it has a fractured urban data ecosystem. This can be illustrated through a comparison of Boston's, Cambridge's and Somerville's data-driven initiatives, selected because they all have active data initiatives.

The City of Boston is by far the largest municipality in the Metro Boston region by population and is highly data driven. It is run by an elected mayor and its data initiatives are principally organized through the Mayor's Office or the Department of Innovation and Technology. The city has appointed a chief information officer and a chief data officer and has several specialist data teams (with over 35 staff), including a New Urban Mechanics (NUM) that works with communities, companies and universities to develop civic apps and data-driven projects. In addition, other departments have significant data capabilities through their work programmes, and the city has 'about 50 data coordinators in departments ... who are essentially tasked with being the liaisons between the source data that comes from these departments and agencies to the open data portal' (SB23).

Cambridge is the second largest municipality in Metro Boston and home to Harvard University and MIT. It is run by a city manager appointed by an elected council. It is separated from the City of Boston by the Charles River. Its data initiatives are organized within the Department of Information Technology, headed up by a chief information officer. As of 2016, it had a relatively large geographical information system (GIS) team (nine staff), but had only recently appointed an open data coordinator and had begun to build out its open data site, but it had not embraced performance management and had relatively little data analytics capabilities. It had no equivalent operation to NUM, though it does participate in some university research projects.

Somerville is the sixth largest municipality in Metro Boston (population of 78,526 in 2013) and borders both Cambridge and the City of Boston. It is run by an elected mayor, now in his seventh term, who has consistently promoted data-driven government, transparency and management reform. Somerville's key data initiatives are organized through the Mayor's Office for Innovation and Analytics. Somerville was the first Metro Boston municipality to embrace data-driven performance management. SomerStat, ${ }^{3}$ a team of five people, employs performance analytics on operational data to supervise the work of city departments and guide budgetary planning, and also create community data profiles and facilitate civic engagement through its ResiStat programme. ${ }^{4}$ In 2016 , it was still in its infancy regarding open data provision.

While Boston, Cambridge and Somerville each have their own approaches to managing and using data for the purposes of city administration, they have very little interaction with each other with respect to data. They have no formal programmes of sharing data or expertise with each other and operate entirely independently, mirroring the governance framework. As one interviewee noted, 'we are very nuclear [with] very little data sharing between municipalities in general' (SB4a). They recognized that in other parts of the country that the county scale would provide structured coordination: 'Boston, Cambridge and Somerville each [has] their own separate data portal because there isn't a lot of services being provided in that umbrella of the county where we might aggregate up' (SB5c). The predominant form of communication was through personal networks rather than formalized relationships. As SB12 noted: 'at one level, informally there is a lot of conversation that goes on ... there are also these really intense rivalries'. The three municipalities are competing with each other for investment, businesses and residents and want to have systems and governance that will give them a competitive advantage, despite the widely documented productivity and economic benefits of more cooperative approaches (Ahrend et al., 2014). Even when similar initiatives are being realized, municipalities might implement a different version, which in turn might produce data with varying ontologies that make it difficult to conjoin data sets. A sharing tradition and culture is also missing within municipalities where 'little fiefdoms' (SB14) hinder collaborative knowledge building 'across those verticals' (SB1b).

When interviewees were asked about data-driven governance in the other 98 municipalities, the opinion expressed was that there was relatively few initiatives. Newton and Lowell both had some experience in using performance management analytics, and some departments across all municipalities might be data-led and proficient. In general, however, municipalities were thought to have little resource and skills capacity, had very basic open data sites, if at all, weakly coordinated data systems, and adhoc data and digital strategies. One city official confessed that he had 'never been at a meeting where I have met somebody from one of those smaller municipalities, it has always been one of these big three'. One academic lamented that the urban data ecosystem 'is totally balkanised' (SB12).

To try to combat this fragmented landscape and provide some consistency and coherence across Metro Boston, there are some cross-cutting data initiatives than span municipalities, though each has its constraints. At the state level, Mass GIS (Bureau of Geographic Information) ${ }^{5}$ provides a state-wide database of geospatial information and a standardized set of 'turnkey solutions' (SB18) (preprepared online GIS) for smaller municipalities that lack the resources to build their own, and negotiate state-wide procurement and software licensing of ESRI (provider of 
ArcGIS software) products. However, it does 'very little in terms of standardisation of local data sets across municipalities' (SB15). While Nelles et al. (2018) argue that the role of the state in influencing and enabling coordination in fragmented governance systems is critical, Mass GIS is a rather limited intervention.

Initiated in 2008, New England StatNet is an initiative administered by the Collins Center for Public Management at the University of Massachusetts Boston to work with municipalities to address resource and data skills capacity issues and promote the use of data-driven performance management approaches (Ward \& Smith, 2013). It organizes regular workshops and seeks to identify methods and best practices for using data to improve government services. It is a voluntary programme with limited resources and has no authority to direct the work of cities and towns. However, it could potentially play an important advocacy function in building regional thinking if it could identify some 'rallying points around which interjurisdictional cooperation can evolve' (Nunn \& Rosentraub, 2007, p. 207).

The MAPC is the only institution specifically focused on the metro-region. It is a quasi-state planning agency whose mission is to 'promote smart growth and regional collaboration' (MAPC, 2015). ${ }^{6}$ As part of its mandate, it works with the 101 municipalities in the metro-region to produce a non-statutory, non-binding regional plan, facilitates shared procurement of services, and provides a standardized set of administrative and statistical data that municipalities or their citizens (e.g., via the census) have to provide to the state or federal agencies. It also provides a set of data tools (e.g., online mapping), facilitated the development of Commonwealth Connect (a shared nonemergency services app provided by a private company), has participated in programmes designed to harmonize performance metrics and data standards, and performs data-led planning consultancy for municipalities. However, it has no authority and a weak formal mandate with respect to municipalities. It possesses little administrative data beyond that sought by the state/federal agencies and no municipal operational data. Despite the potential that this scale of governance might offer, such as in many other contexts, it has not resulted in practice in the 'development of regional institutional frameworks for co-operation and co-ordination' (Meijers \& Romein, 2003, p. 180).

The Boston Area Research Initiative set up in 2011 is an inter-university initiative that works with the City of Boston, and to a lesser degree with Cambridge and Somerville, with respect to urban data and data issues. It seeks to make available data sets and maps through its Boston Data Portal $^{7}$ that are useful for scholarly urban research, an aspect of which requires harmonizing data from different jurisdictions. Its primary remit is to conduct academic and policy-led research using the City of Boston as a case study, rather than to provide data services or act as a coordinating data infrastructure for the metro-region.

In addition to public agencies and university initiatives, several private companies (e.g., digital platforms, sharing economy, utility companies, etc.), whose operations and markets span cities and towns, are generating data across the region that would be of benefit to public administration. While some of these companies do have partnerships with municipalities (e.g., Waze is exchanging its real-time traffic data for details of road construction and closures with one city; SB1b), there is no centralized data exchange for companies or municipalities.

\section{ISSUES}

The fractured urban data ecosystem in Metro Boston creates several related issues, with inefficiencies in organization, uneven resourcing and lack of scales of economy producing interjurisdictional data incompatibilities that reduce spatial intelligence, foster back-to-back planning and stifle the benefits of open data. This lack of coherence and integration mirrors and is a product of fragmented governance structures and a lack of 'regional' thinking, capacity and culture (Hamilton, 2004). It inhibits synergistic metropolitan development, widely acknowledged as a core issue in the housing affordability crisis across the metro-region (Glaeser, 2014), impacting on the attractiveness of the city (Pike, Rodríguez-Pose, \& Tomaney, 2016), and precluding the creation of a regional data economy.

\section{Inefficiency, uneven resourcing and scale of economy}

There is little doubt that having 101 cities and towns in Metro Boston working to develop data-driven governance and services, create and maintain data infrastructures, and produce open data creates a large duplication of effort and inefficiencies in procurement. With the exception of the City of Boston, given its size and relative wealth/purchasing power, cities and towns lack the scale of economy needed to leverage efficiency savings that could be gained through collaboration and the pooling of efforts and budgets. At the same time, there is highly uneven resourcing and skills capacity across these cities and towns to develop high quality, well-maintained data-driven systems and services. As a consequence, every municipality is performing suboptimally and some are being left behind, unable to realize the benefits that being data-driven might produce and exacerbating pre-existing intraregional inequalities between the central urban core and wider region (Sullivan, 2013). As a state official noted: 'Boston [has] more bandwidth to do these sort of things and more data, just because of the scale' (SB1b). Cambridge and Somerville are following a data-driven path, but their resourcing and programmes are a fraction of the City of Boston. As one academic detailed: 'It is a small city problem.... Cambridge and Somerville are doing some interesting things but they don't have a lot of capacity' (SB17), although they are well ahead of other cities and towns. While MAPC does act in some cases as a broker for shared services and does provide some open data and analytics functions, this falls far short of what a collaborative, shared data ecosystem might look like. 


\section{Data incompatibilities}

A fractured data landscape, resourcing deficits and lack of scales of economy produces significant data issues with respect to creating comparable cross-jurisdictional data sets and gaining an understanding of the performance of the metro-region as a whole. With the exception of data required for state/federal reporting, each municipality is free to generate whatever data it wishes and to create its own data ontologies. This is compounded by a 'lack of standardised workflows ... and no data standards' (SB15) across the metro-region. The result is data related to administration and operations are unevenly generated, and those data that are generated might be inconsistent in nature across jurisdictions, meaning they cannot be conjoined and used productively (O'Brien, 2015). However, given the strength of the 'home rule' and autonomous tradition within the metro-region, whether political actors even recognize this problem is unclear as 'their understanding ... is affected by the values and beliefs that they hold' (DiGaetano \& Strom, 2003, p. 372).

\section{Reduced spatial intelligence and back-to-back planning}

The lack of harmonized data at the metro-region scale significantly reduces spatial intelligence that would aid both internal operations and planning, and also metro-region wide infrastructure, economic development and spatial planning. In effect, it is difficult to obtain the 'big picture' (SB1b) or to look at patterns of behaviour and the functional territories of activities that span jurisdictions. As SB1b continued: 'there is no way to see if Boston reduced its crime, but crime went up in Cambridge because it just moved down the block'. Further, it reinforces back-toback planning, as it becomes difficult to assemble relevant, equivalent data for the surrounding municipalities. During the fieldwork both the City of Boston and Cambridge, which share a border, were producing master plans independently of each other. The vast majority of maps produced by the City of Boston do not include data relating to the surrounding cities and towns, even though there is an irregular-shaped border around Brookline and Cambridge. Yet, what happens in its neighbouring administrative areas directly affects its own fortunes. Figure 2 displays the city's climate ready map, an issue that has consequences, and demands a coordinated strategy, across the whole metro-region. Barely acknowledging that neighbouring municipalities and their data ecosystem exist, and failing to collaborate actively with them, is a very limited and limiting position, and is contrary to trends in other major metropolitan regions where the 'neighbour effect' is recognized as of significant import (Brown, Eden, \& Bosetti, 2018).

\section{Stifling the benefits of open data}

In addition to limited spatial intelligence and limiting the work of public administration, the lack of harmonized data and a coherent metro-region data ecosystem stifles the potential of open data. One of the key reasons for opening data is to enable the value of public data to be leveraged into products, whether that be non-for-profit civic apps, or for-profit commercial apps (Pollock, 2009). Indeed, open data are seen as a key ingredient in efforts to create data economies. Moreover, many of these civic apps seek to make the work of government transparent, accountable and comparable, and also enable the public to become more informed about issues and facilitate public participation in the civic realm and foster social innovation (Kitchin, 2014). Open data also encourages public agencies to use such data to improve operational efficiencies and productivity through evidence-informed monitoring and decision-making, plus they can get valuable feedback from outside parties. None of these benefits, however, can be realized if there are systemic inconsistencies in data ontologies across related data sets, a lack of open data and disincentives to cooperation. Smart city technologies, such as civic apps, need to be able to scale across jurisdictions to create viable markets and revenue streams. Developers do not expect to have to expend time and energy hunting across 101 open data repositories for data, talking to officials to get clarity, perform significant data wrangling to get comparability, or produce endless bespoke apps that cannot scale. Consumers expect to use one app that relates to multiple jurisdictions. This is all but impossible in Metro Boston and seriously limits the opportunities of leveraging open data.

\section{TOWARDS A CITY-REGION DATA COMMONS?}

In many multi-jurisdictional cities, there are initiatives that seek to provide coherence and integration across operational and strategic domains in the collective interest. While in some places new regional or metropolitan scale institutions are created, in other contexts effective partnership networks operate without institutionalization (Feiock, 2009; Nelles, 2013). The creation of a citywide data commons, a shared set of data tools and an aligned approach to data-driven urbanism, can be facilitated by governance structures that support and incentivise municipalities to share data and work collaboratively. For example, in Los Angeles, the county government provides a single open data portal and services for all sixty municipalities within its jurisdiction. ${ }^{8}$ In New York, the Mayor's Office provides a common agenda and platform for the five boroughs through the open-data team and the Mayor's Office of Data Analytics. ${ }^{9}$ Similarly, in London (UK), all 32 boroughs are mandated to share data with the Greater London Authority (GLA) and have access and contribute to some shared data services. ${ }^{10}$ In these cases, the municipalities/ boroughs continue to manage their own data infrastructures and digital services, but do so mindful that they are operating within a larger framework, including a wider spatial planning remit that requires alignment at the metropolitan scale.

As noted, this is not the case in Metro Boston, where the fragmented governance landscape is strongly embedded and there is no perception that cooperation could yield 


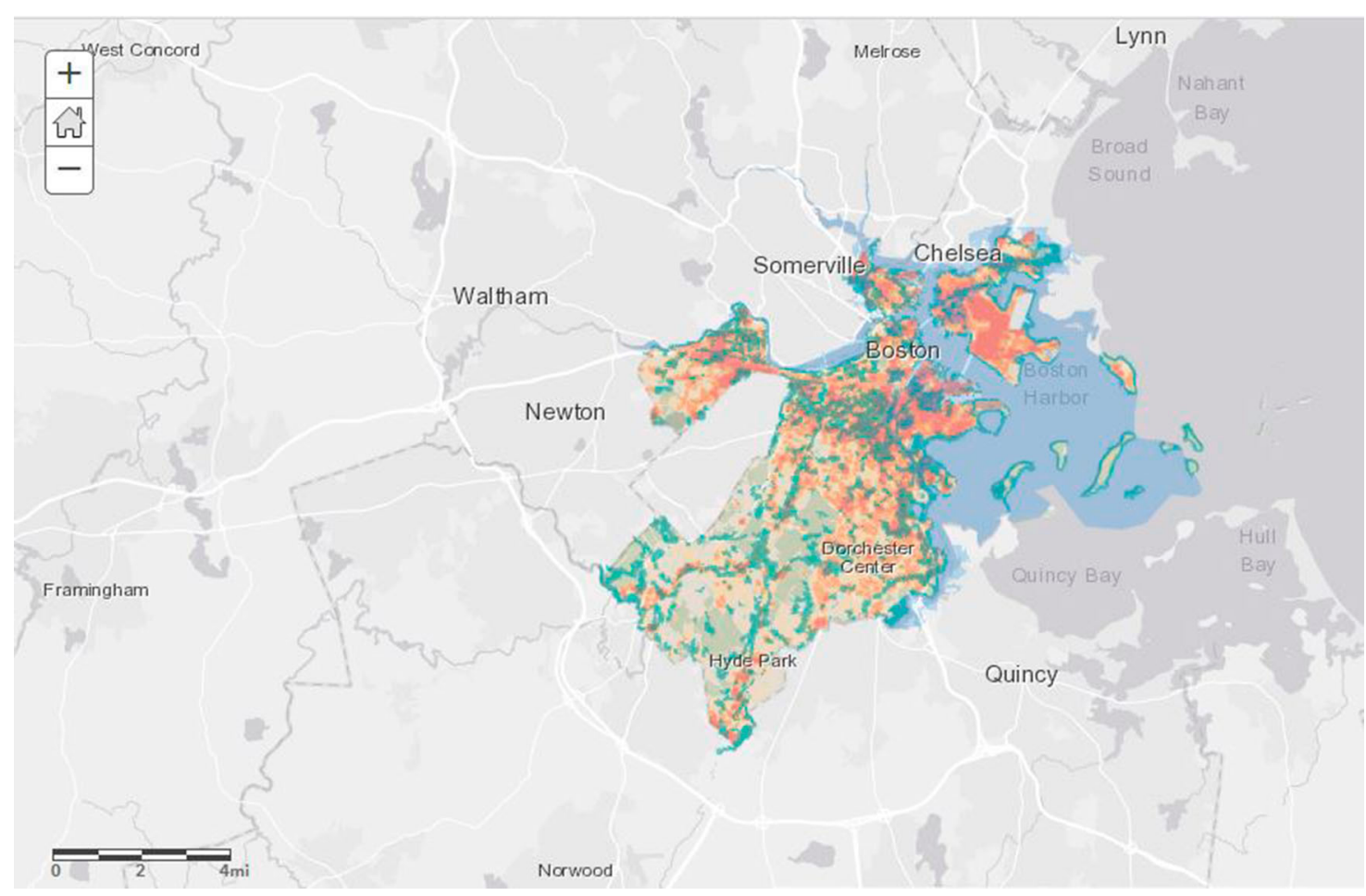

Figure 2. City of Boston, Climate Ready Boston Map.

Source: Screenshot, City of Boston, Boston Maps (http://boston.maps.arcgis.com/home/index.html).

advantages (Hamilton, 2004). Such fragmentation is justified as providing checks and balances to accumulated power, enabling diverse and creative approaches to policy, and creating choice between locales and services. However, there is a fine line between creative complexity and unruly fragmentation (Euncher, 2003) and there are examples of 'low risk' cooperative models that do not diminish local autonomy (Nunn \& Rosentraub, 2007). The case of the urban data ecosystem in Metro Boston demonstrates no desire or expectation to simplify and align. While Mass GIS, New England Stat Net, MAPC and BARI work to paper over some of the cracks, they are relatively small enterprises focused on planning, core indicators, performance management and academic policy research. Yet, several respondents noted that there was a 'tremendous interest among citizens, among developers, among housing advocates, among environmental folks, state agencies' (SB15), and other stakeholders for metro-region data and data tools.

While it is tempting to suggest deep political restructuring through the introduction of regional government as a solution to fragmentation, neither citizens nor municipalities have an appetite for a new form of regional administration (Horan, 2009; McCauley \& Murphy, 2013; O'Connell, 2002). This is especially the case where it would be perceived to undermine local autonomy, as the repeated rejection of regional metropolitan government in Metro Boston over the past century has highlighted (O'Connell, 2002). Similarly, a state-level mandate for additional data or for collaborative shared data services will run into stiff political resistance. As one public official stated: 'You can't mandate to the municipalities, they will just tell you to $\mathrm{f}^{* * * *}$ off; it will never get through the legislature' (SB15). Nonetheless, there is some evidence from elsewhere that the state could play a critical role in the economic development of the Boston metropolitan region (Pike et al., 2016).

A more viable solution with respect to creating a metropolitan data commons is a compact between the cities and towns that would formalize data sharing and services across Metro Boston. Such a compact would operate as a form of 'competitive collaboration' (Johnsen \& Ennals, 2012), working for the collective benefit of all cities and towns by creating shared value by providing data infrastructures, data sets and services for the metro-region that would aid local planning and operations; provide a data commons that would support a viable open data economy; act as a point of contact for collaborations with industry, universities and civic groups; and provide a node around which those interested leveraging urban data in diverse ways could gather. This would not necessarily prevent them from developing their own data-driven services and initiatives that might provide competitive advantage in terms of economic development and quality of life. In other words, it would provide the basis for a more coordinated and coherent urban data ecosystem.

This has been the approach adopted in Dublin (Ireland) through the creation of Dublinked, the city's open data site, and Smart Dublin, a shared smart cities office. ${ }^{11}$ Like Boston, local government in Dublin is fragmented and there is limited cooperation between authorities (Moore-Cherry \& Tomaney, 2019), and no city-regional government. ${ }^{12}$ However, the four Dublin authorities voluntarily agreed to take a common approach to open data and smart cities 
in 2010, recognizing the scales of economy and shared benefits of a single open data portal and a loosely coordinated approach to data-driven urbanism (Coletta, Heaphy, \& Kitchin, 2019). ${ }^{13}$ This admittedly is a rare case of formalized collaboration and shared ownership and Smart Dublin/Dublinked is presently the only mainstreamed, long-term initiative of the four Dublin authorities.

MAPC is presently the agency nearest to performing this role in Metro Boston. However, it does not operate as a collectively owned, shared initiative of all cities and towns (it is an independent regional planning agency) and has no authority. Moreover, there is a sense that MAPC is providing a minimum-level data and services platform for those cities and towns which lack the capacity to develop their own data infrastructure and analytics, with the more capable municipalities largely taking their own path. However, in its favour is that it already exists, has a board that includes the chief elected officials of the 101 cities and towns, representatives from state agencies, and citizen appointees of the governor, and citizens in Metro Boston do favour 'cooperative action' between municipalities (O'Connell, 2002). Such a compact would be strengthened significantly if other public agencies, such as MBTA, MHFA, and MWRA were members, and if data-sharing agreements at the city-regional level could be reached with private companies.

Whether such a meaningful collaborative venture is possible in practice is somewhat doubtful. The local autonomy of municipalities is well entrenched, with one city official explicitly rejecting the Dublin model for this reason:

And in the case of Dublin you do need that unified portal of all four. It is not like Boston and Cambridge. If I am interested in Boston, I am interested in Boston, or I am interested in Cambridge, but in Dublin you kind of need that whole picture.... We don't care once you go across the river!

Here, there was a perception that Dublin was a single city split into four jurisdictions, whereas Boston was 101 separate, autonomous cities and towns. Another city official rejected a collaborative approach on similar grounds.

But each of these cities have their very distinct identity. So, Somerville has a very distinct identity. Cambridge, for sure, has a very distinct identity. So to say that we can all coalesce around one portal, may be a bit of a challenge because from a cultural perspective they may all say, no we are different from you and here is how we want to do it.

$(\mathrm{SB} 6 \mathrm{c})$

Wheeler (2009) has argued that the emergence of strong regional groups is challenging where local political actors are reluctant to relinquish power as part of a rescaling. This is clearly evident in Metro Boston where one respondent (SB19) concluded that: 'they have almost nothing and what they have they are not going to give up'. With respect to a regional data commons, this would translate as: 'So, we will decide our own data policy because we can't decide anything else' (SB19). One public official thus noted that:

It requires a tremendous amount of labour to get communities to agree on [anything]. ... It is a city of cities and everybody feels like they are a special snowflake and we can't possibly have the same system as the community next door that is almost exactly the same size with almost exactly the same demographics and land use.

City officials, some of whom recognized the value of federated data sets and shared services, expressed this view, detailing reasons as to why they were unlikely to pursue a shared approach. For example, one official professed to be in favour of data standards that would create harmonious metro-region data sets, but he also wanted to 'make sure that taxpayers dollars in [this municipality] go to helping [this municipality's] residents' (SB18). The same interviewee admitted that they were cautious about creating federated data sets because it would mean having to 'compromise on your data standards and have a lot of meetings about your data collection processes and business standards', noting that, as the city adopts performance metrics and statistics and analysis, 'it is going to become harder to cooperate with our neighbours' (SB18) due to embedded legacy data systems. In other words, the present rolling out of different data systems across cities and towns, along with a lack of data standards, is likely to make a coherent urban data ecosystem increasingly difficult to achieve.

Similarly, an official in another municipality argued that 'most cities and towns ... are really strapped for time and resources and having to devote additional time to rejigging our data collection processes so that they are the same as their neighbours, I think it is a slog' (SB22a). On the one hand, the City of Boston has sufficient scale and a sophisticated data infrastructure and suite of data services that makes collaboration seem unnecessary. Plus, it was felt that their inclusion meant the playing field was never level with respect to collaboration: 'Boston is always the biggest dog in the room' and 'it is hard for other communities to have a say and feel validated as part of [any] process' (SB22b). On the other hand, not all cities and towns have the resources to prepare and contribute data to a collaborative, shared data platform, or the political will or capacity to change internal systems to be able to supply data beyond what they presently provide to the state and federal agencies. Even with some higher level technical and analytical functions being centralized, becoming data-driven requires an overhaul of local data management practices and an investment in personnel. One city official estimated that the cost of preparing its data for the open data portal is up to US $\$ 150,000$ a year in excess of usual operating costs and it has a skilled team of data literate staff. Some towns have semi-professional or voluntary staff who have low levels of technical and data literacy and tightly constrained budgets.

Thus, one academic concluded: 
I think if you went to talk to a lot of these small municipalities, they would agree [a shared data platform] would make sense but they would have no idea how they could possibly think about this issue because what they are worried about is their schools are not actually working and the police force is falling apart and that is as much as they could handle, and could you come back in a couple of years.

The result, as a private sector actor summarized, is there are 'really well resourced folks that are afraid ... to give up resources, and then you have these folks who can't even think about it because it is so far down on their priority list' (SB16). In such a fractured and unevenly resourced political landscape, the best one might presently be able to hope for is the MAPC to expand its data role and remit, and a set of incentives (e.g., additional funding streams) or expectations (e.g., embedding in regulatory and programmatic requirements) are put in place by the state to encourage collaboration. Drawing on the experience in other fragmented metropolitan regions that have highly competitive tendencies, there may be merit in beginning with a sub-metropolitan flexible response that begins with a 'coalition of the willing' and is fluid in nature (Henderson, 2018). Another possibility is that the open data movement and the private sector drives the creation and adoption of standards across public bodies, as with the open311 standard for citizen reporting of issues to administrations. This standard has been adopted by several Metro Boston municipalities, though their front-end design, app name and vendor varies (e.g., Citizens Connect, Commonwealth Connect, SeeClickFix, Cambridge i-reports, BrookOnline) (Offenhuber, 2015).

\section{CONCLUSIONS}

Metro Boston is somewhat of an unusual case - though by no means unique - with respect to its urban governance given the scale and depth of horizontal fragmentation across municipalities and a lack of vertical integration. Nonetheless, it does highlight the effects of fragmented governance on the urban data ecosystem and data-driven urbanism. As detailed, the fragmentation of administration clearly has profound effects, creating inefficiencies in organization, a lack of scales of economy and data incompatibilities that reduce spatial intelligence, foster back-toback planning and stifle the benefits of open data. Territorial politics and a strongly embedded tradition of local autonomy and belief in self-government, combined with uneven resourcing and capacity, hinder collaboration generally and the creation of coherent metro-region data sets and shared data services specifically. In this case, path dependency is acting as a critical brake on potential innovative approaches to urban governance and management.

This fragmentation also helps to explain, as hypothesized by Kitchin et al. (2017a), the 'adoption gap' in the uptake of smart city technologies, not just in Boston but globally. Such technologies are designed to work at scale and across jurisdictions, rather than being deployed in bespoke form across cities. Fragmented governance splits potential markets into a myriad of municipalities that have different ethos, priorities, structures, resources, finances, and legacy infrastructures and systems. While each municipality could invest in a particular smart technology, it only becomes cost-effective and its utility and value realized when it is operated at scale. Each of the 101 municipalities in Metro Boston investing in its own intelligent transport system or city operating system or having its own bikeshare scheme that is not interoperable across the metro-region, for example, would make little sense. Metro-wide adoption, at a sufficient scale of economy, can only be achieved through collaborative procurement, which is difficult to realize in practice, particularly given the structural differences between the municipalities, many of which have a strong rural character despite being in the metro area.

In the past, key infrastructures and services - water, sewage, public transit, main roads - were extracted from municipalities and placed into regional entities that spanned them (e.g., in the Metro Boston case, MBTA, MWRA). Such extraction would make sense with respect to many new digital, data-driven infrastructures and services. However, creating new regional agencies is politically challenging. In the Metro Boston case, such a move would be strongly resisted, especially since many of these infrastructures and services relate to the core operational business of municipalities that historically and culturally have been highly autonomous. The MAPC does offer a potential route to a more coherent urban data ecosystem and a metro-region-wide approach to data-driven urbanism. However, the civic capacity required to do this is lacking. Despite 'intermunicipal partnerships [being] at the heart of city-region governance capacity' (Nelles, 2013, p. 1355), building consensus and commitment with political actors across different territories and scales is difficult. In the United States, there is no incentive for political leaders to engage in regional thinking, yet without it, the performance of any city-regional institution will be severely hampered (Hamilton, 2004). The Organisation for Economic Co-operation and Development (OECD) suggests that the factors limiting effective multilevel governance systems include asymmetries of information, lack of capacity and policy fragmentation, and that overcoming these challenges requires 'instruments for revealing and sharing information' (Tomaney, 2016, p. 550). A smart and integrated urban data ecosystem could fundamentally alter existing intragovernmental and intra-municipal relationships and perhaps this is the key problematic in a very conservative, rigid, localist system.

This analysis highlights that the study of smart cities, open data and data-driven urbanism needs to pay more attention to the territorial politics of metropolitan development. Far too often, critical analysis of smart cities has treated technologies and data as political, but have treated the organization of city-regional governance in a relatively benign, universal way. The present case study, and the vast literature on urban governance, makes clear this is far from being the case. As such, more research is required 
to unpack the effects of multi-jurisdictional governance on the adoption of technologies and practices. Such research needs to examine the effects of different organizational forms of urban governance regimes on urban data ecosystems and digital infrastructures. In particular, it is necessary to examine multilevel and functional governance regimes with respect to different technologies and forms of urban data. There is also a need to examine further the effects of data-driven technologies on the forms and practices of municipal government, and how these are ameliorated by governance regimes in order to make sense of how the 'actually existing smart city' (Shelton et al., 2015) is unfolding.

\section{ACKNOWLEDGEMENTS}

The authors thank the interviewees who took part in the research; and Lily Perkins-High and Tim Reardon at MAPC for producing Figure 1.

\section{DISCLOSURE STATEMENT}

No potential conflict of interest was reported by the authors.

\section{FUNDING}

The research for this paper was funded by an H2020 European Research Council (ERC) Advanced Investigator award, 'The Programmable City' [grant number ERC2012-AdG 323636-SOFTCITY].

\section{NOTES}

1. See https://factfinder.census.gov/faces/tableservices/ jsf/pages/productview.xhtml?src=bkmk (see also https:// statisticalatlas.com/metro-area/Massachusetts/Boston/ Population\#data-map/county-subdivision).

2. The BRA has subsequently been renamed the Boston Planning and Development Authority.

3. See https://www.somervillema.gov/departments/mayor/ somerstat/.

4. See https://www.somervillema.gov/resistat/.

5. See https://www.mass.gov/orgs/massgis-bureau-ofgeographic-information/.

6. See https://www.mapc.org/aboutus/.

7. See https://www.northeastern.edu/csshresearch/bos tonarearesearchinitiative/boston-data-portal/.

8. See https://data.lacounty.gov/.

9. See https://opendata.cityofnewyork.us/overview/.

10. See https://data.london.gov.uk/.

11. See https://www.smartdublin.ie/.

12. The Eastern and Midland Regional Assembly, one of three such assemblies in Ireland, coordinates regional spatial planning, but it has a narrow role and very little authority over local authorities (see https://emra.ie/).

13. See http://www.smartdublin.ie/.

\section{ORCID}

Rob Kitchin (1) http://orcid.org/0000-0003-4458-7299

Niamb Moore-Cherry (10 http://orcid.org/0000-0003-03728809

\section{REFERENCES}

Ahrend, R., Farchy, E., Kaplanis, I., \& Lembcke, A. C. (2014). What makes cities more productive? Evidence on the role of urban governance from five OECD countries (OECD Regional Development Working Papers). Paris: Organisation for Economic Co-operation and Development (OECD).

Barns, S. (2016). Mine your data: Open data, digital strategies and entrepreneurial governance by code. Urban Geography, 37(4), 554-571. doi:10.1080/02723638.2016.1139876

Barns, S. (2018). Smart cities and urban data platforms: Designing interfaces for smart governance. City, Culture and Society, 12(1), 5-12. doi:10.1016/j.ccs.2017.09.006

Bevir, M., \& Rhodes, R. A. (2003). Interpreting British governance. London: Routledge.

Brown, R., Eden, S., \& Bosetti, N. (2018). Next door neighbours Collaborative working across the London Boundary. London: Centre for London and Southern Policy Centre.

Coletta, C., Heaphy, L., \& Kitchin, R. (2019). From the accidental to articulated smart city: The creation and work of 'smart Dublin'. European Urban and Regional Studies, 26(4), 349-364. doi:10. 1177/0969776418785214

DiGaetano, A., \& Strom, E. (2003). Comparative urban governance: An integrated approach. Urban Affairs Review, 38(3), 356-395. doi:10.1177/1078087402238806

Euncher, C. (2003). Governing greater Boston: Fragmented bodies, fragmented policies. In C. Euchner (Ed.), Governing greater Boston: Meeting the needs of the region's people (pp. 1-38). Cambridge, MA: Rappaport Institute for Greater Boston.

Feiock, R. C. (2009). Metropolitan governance and institutional collective action. Urban Affairs Review, 44(3), 356-377.

Frug, G. E., \& Barron, D. J. (2008). City Bound: How states stifle urban innovation. Ithaca: Cornell University Press.

Gil-Garcia, J. R. (2012). Towards a smart state? Inter-agency collaboration, information integration, and beyond. Information Polity, 17(3-4), 269-280. doi:10.3233/IP-2012-000287

Glaeser, E. (2014, July 27). What Greater Boston can teach the rest of the world. Boston Globe.

Goldsmith, S., \& Crawford, S. (2014). The responsive city: Engaging communities through data-smart governance. Chichester: Wiley.

Hamilton, D. K. (2004). Developing regional regimes: A comparison of two metropolitan areas. Journal of Urban Affairs, 26(4), 455-477. doi:10.1111/j.0735-2166.2004.00210.x

Hamilton, D. K., Miller, D. Y., \& Paytas, J. (2004). Exploring the horizontal and vertical dimensions of the governing of metropolitan regions. Urban Affairs Review, 40(2), 147-182. doi:10. 1177/1078087404268077

Henderson, S. (2018). Competitive sub-metropolitan regionalism: Local government collaboration and advocacy in northern Melbourne, Australia. Urban Studies, 55(13), 2863-2885. doi:10.1177/0042098017726737

Henderson, S. R. (2015). Transforming old industrial regions: Constructing collaboration within the Black country, England. Geoforum, 60, 95-106. doi:10.1016/j.geoforum.2015.01.010

Horan, C. (2009). The politics of competitive regionalism in greater Boston. Journal of Urban Affairs, 31(3), 349-369. doi:10.1111/j. 1467-9906.2009.00463.x

Johnsen, H. C. G., \& Ennals, R. (2012). Creating collaborative advantage: Innovation and knowledge creation in regional economies. Farnham: Gower. 
Karvonen, A., Cugurullo, F., \& Caprotti, F. (Eds.). (2018). Inside smart cities: Place, politics and urban Innovation. London: Routledge.

Kitchin, R. (2014). The data revolution: Big data, open data, data infrastructures and their consequences. London: Sage.

Kitchin, R., Coletta, C., Evans, L., Heaphy, L., \& Mac Donncha, D. (2017a). Smart cities, urban technocrats, epistemic communities, advocacy coalitions and the 'last mile' problem. it - Information Technology, 59(6), 275-284.

Kitchin, R., Lauriault, T., \& McArdle, G. (2015). Knowing and governing cities through urban indicators, city benchmarking and real-time dashboards. Regional Studies, Regional Science, 2, 1-28.

Kitchin, R., Lauriault, T. P., \& McArdle, G. (Eds.). (2017b). Data and the city. London: Routledge.

Kreukels, A. (Ed.). (2003). Metropolitan governance and spatial planning: Comparative case studies of European city-regions. London: Taylor \& Francis.

Light, J. S. (2004). From warfare to welfare: Defense intellectuals and the urban problems in Cold War America. Baltimore: Johns Hopkins University Press.

McArdle, G., \& Kitchin, R. (2016). Improving the veracity of open and real-time urban data. Built Environment, 42(3), 457-473. doi:10.2148/benv.42.3.457

McCauley, S. M., \& Murphy, J. T. (2013). Smart growth and the scalar politics of land management in the greater Boston region, USA. Environment and Planning A: Economy and Space, 45, 2852-2867. doi:10.1068/a45307

Meijers, E., \& Romein, A. (2003). Realizing potential: Building regional organizing capacity in polycentric urban regions. European Urban and Regional Studies, 10(2), 173-186. doi:10. 1177/0969776403010002005

Metropolitan Area Planning Council (MAPC). (2015). Metropolitan Area Planning Council strategic plan 2015-2020. Boston: MAPC. Retrieved from https://www.mapc.org/wp-content/uploads/ 2017/08/FINAL-StrategicPlan-12-2-14-web.pdf.

Miller, D. Y., \& Lee, J. H. (2011). Making sense of metropolitan regions: A dimensional approach to regional governance. Publius: Journal of Federalism, 41(1), 126-145. doi:10.1093/ publius/pjp040

Moore-Cherry, N., \& Tomaney, J. (2019). Spatial planning, metropolitan governance and territorial politics in Europe: Dublin as a case of metro-phobia? European Urban and Regional Studies, 26 (4), 365-381. doi:10.1177/0969776418783832

Nelles, J. (2013). Cooperation and capacity? Exploring the sources and limits of city-region governance partnerships. International Journal of Urban and Regional Research, 37(4), 1349-1367. doi:10.1111/j.1468-2427.2012.01112.x

Nelles, J., Gross, S., \& Kennedy, L. (2018). The role of governance networks in building metropolitan scale. Territory, Politics, Governance, 6(2), 159-181. doi:10.1080/21622671.2017. 1421478

Norris, D. F. (2017). Metropolitan governance in America. London: Routledge.
Nunn, S., \& Rosentraub, M. S. (2007). Dimensions of interjurisdictional cooperation. Journal of the American Planning Association, 63(2), 205-219. doi:10.1080/01944369708975915

O'Brien, D. (2015). Custodians and custodianship in urban neighborhoods: A methodology using reports of public issues received by a city's 311 hotline. Environment and Behaviour, 47(3), 304327. doi:10.1177/0013916513499585

O'Connell, J. C. (2002). Thinking like a region: Historical and contemporary perspectives. In C. Euncher (Ed.), Governing greater Boston: The politics and policy of place (pp. 31-64). Cambridge, MA: Rappaport Institute for Greater Boston.

Offenhuber, D. (2015). Infrastructure legibility - A comparative analysis of open311-based citizen feedback systems. Cambridge Journal of Regions, Economy and Society, 8(1), 93-112. doi:10. 1093/cjres/rsu001

Patton, M. (1990). Qualitative evaluation and research methods. London: Sage.

Pike, A., Rodríguez-Pose, A., \& Tomaney, J. (2016). Local and regional development (2nd Ed.). London: Routledge.

Pollock, R. (2009). The economics of public information (Cambridge Working Papers in Economics No. 0920). Retrieved from http://www.econ.cam.ac.uk/research/repec/cam/pdf/cwpe0920. pdf.

Ruhlandt, R. W. S. (2018). The governance of smart cities: A systematic literature review. Cities, 81, 1-23. doi:10.1016/j.cities. 2018.02.014

Scholl, H. J., \& AlAwadhi, S. (2016). Smart governance as key to multi-jurisdictional smart city initiatives: The case of the eCityGov Alliance. Social Science Information, 55(2), 255-277. doi:10.1177/0539018416629230

Shelton, T., Zook, M., \& Wiig, A. (2015). The 'actually existing smart city'. Cambridge Journal of Regions, Economy and Society, 8 (1), 13-25. doi:10.1093/cjres/rsu026

Sullivan, R. D. (2013, May 26). Boston's reasserted dominance of New England, in three charts. Retrieved from https://robertdavidsullivan. typepad.com/my_weblog/2013/05/boston-reasserted-dominancenew-england-census-population-2012.html

Tewdwr-Jones, M. (2012). Spatial planning and governance. Basingstoke: Palgrave Macmillan.

Tomaney, J. (2016). Limits of devolution: Localism, economics and post-democracy. Political Quarterly, 87(4), 546-552. doi:10. 1111/1467-923X.12280

Townsend, A. (2013). Smart cities: Big data, civic Hackers, and the Quest for a New Utopia. New York: W. W. Norton.

Ward, M. J., \& Smith, A. E. (2013). New England StatNet: A community of practice in performance measurement (Paper No. 148). Boston: Edward J. Collins, Jr. Center for Public Management, University of Massachusetts, Office of Community Partnerships Posters. Retrieved from http://scholarworks.umb.edu/ocp_ posters/148.

Wheeler, S. (2009). Regions, megaregions, and sustainability. Regional Studies, 43(6), 863-876. doi:10.1080/003434007018 61344 